\title{
Breve til og fra Grundtvig, marts - juni 1844
}

\section{Af Jette Holm}

Grundtvigs breve fra slutningen af marts til juni 1844, der dækker den periode, hvor Grundtvig var syg, findes i Breve fra og til N. F. S. Grundtvig (BG II), Peter Rørdam, 1, Blade af hans Levnedsbog og Brevvexling fra 1806-1844 (Rørdam 1891) og Gunni Busck, et Levnedsløb i en Prastegaard (Bech 1878).

Ved en sammenligning med Grundtvig-Registranten viser det sig, at der er adskillige breve i Grundtvigarkivet, også fra denne periode, der ikke er trykt. Et enkelt brev findes uden for Grundtvigarkivet på Det Kongelige Bibliotek, NKS. For at fuldstændiggøre billedet af sygdomsforløbet bringes her de utrykte breve, der berører Grundtvigs sygdom og ophold hos præstevennerne.

Jørgen Ertner har i sin afhandling "Et ord af Guds Søn" (Ertner 1997, 185 ff.) fremdraget et hidtil ukendt brev fra Grundtvig til Ferdinand Fenger, 28. maj 1844. Brevet refereres grundigt; men for oversigtens skyld er det taget med i nedenstående samling af utrykte breve fra denne periode.

Jævnfør desuden Christian Thodbergs artikel i dette nummer af Grundtvig-Studier om Grundtvigs krise i foråret 1844, hvor nedenstående breve inddrages.

\section{Fra Caroline Amalie ${ }^{1}$}

\section{Hr. Pastor Grundvig!}

Hvor inderlig beklager jeg Deres Upasselighed! Faaresyge, hvilken Sygdom og det for Dem! Torsdag var berammet til Kongens Besøg hos os, naturligviis beder jeg om Opsættelse, til Skolens Directeur atter er rask! Her et Brev fra Rørdam, De vil see, at han ogsaa helst giver Kongen Syn for Sagen om hans Anskuelser om Almueskolerne. Men indtil efter Paaske tør jeg neppe bede Kongen forhale hans Besøg, indtil da kunne der mulig være taget en Bestemmelse. I Vaisenhuset, hvor de 3 nye Lærere ere i samme Aand og undervise paa samme Maade som Boisnerne, ville den levende Skole, fordi Børnene ere ældre, og alt der er efter en større Maalestok, muligen blive mere i Øinefaldne, og denne Skole staaer under Stemanns særdeles Protection! $\mathrm{Nu}$ Gud befalet og ligeledes den levende Skole.

God Bedring. Med sand Højagtelse og Hengivenhed. 


\section{Fra Gunni Busck ${ }^{2}$}

Stiftsbjergbye 30te Marts, 1844

Da jeg veed at dit Hjerte Kjære Ven! tager venligen Deel i mine Forhaabninger om Forflyttelse efter Guds Vor Herres Jesu Christi Faders Villie! saa vil jeg dog fortælle Dig, at da jeg talte med Kongen i Fredags efter dit Raad - Brevet kom saaledes da paa Ilden, hvor alle Breve og alle Bøger maae ende og det ikke for at opstaae igjen - var han meget naadig. Førend jeg fik lukket Munden op (og Du veed da at den er ikke af de laasede) nævnte han Barnets Navn, hvorfor han nok tænkte jeg var kommen, spurgte mig om jeg ogsaa kunde være tjent med det Kald, hvortil jeg svarte ja og tilføiede til Grunden om Strandvandets Nærhed for lille Johannes, da vi havde mistet en lille Søn af Kjirtelsyge. Han bemærkede at Præstegaarden var vist i daarlig Stand, hvortil jeg svarede, at jeg ventede intet Godt af hvad Formanden i det Kald efterlod, men haabde med Guds Hjelp at kunne være Noget for Menigheden, naar Kongen vilde betro mig Kaldet. Forresten var han meget naadig, gav vel intet bestemt Løvte, men sagde: "Ja kom nu med Ansøgningen og lad os see hvad Cancelliet skriver!"

Det vil jeg da nu gjøre og saa ville vi faae at see baade hvad Cancelliet skriver og hvad Gud Han siger; thi

Udgaaer Ordet af Kongens Mund,

Som haver Alt at raade

Da kommer jeg tryg til Brøndbylund,

Som kaldet af Guds Naade!

Efter de lyse Udsigter, paa hvilke vi ei maae bygge, men som skulle lære os at bygge paa Ham, der skaber alle Soelglimt, seer det jo godt ud. Saaledes rykker jo ogsaa Dronningens Fødselsdag nær den Tid det skal afgjøres, saa har eller faaer hun herovenfra Lyst til at lægge et venligt Ord ind for mig, da veed man jo, at Geburtsdagsbørn pleie at faae Deres Villie. $\mathrm{Nu}$ - Gud faae sin Villie frem i Alt med os kjære Ven! saa bliver der i ingen Henseende Rum i os til Klage, men Alt i os bliver omsider fuldt af de Lovsangens Toner, som ere søde(?) og velbeha[ge]lige for Vor Faders Hjerte!

Glædelig Fest for Dig og Dine først Glæde over Hans Opstandelse, som kan trøste over alle Nederlag og dernæst ogsaa Glæde over, at Familiefaderen staaer med Guds Hjelp op af sin Faaresygdom inden Paasken!

Din Ven

G. Busck 
Det lader til daarligt Veir ved Thorvaldsens Begravelse; men jeg siger i mit Hjerte: Gud lade ham i Jesu Navn have det godt, hvor han er vandret hen, saa veed jeg han blæser ad alle denne Verdens Ceremonier!

\section{Fra E. Tryde 3}

Hans Høiærværdighed Biskoppen har under 15. d. M. tilskrevet mig saaledes:

"I Adresse-Avisen for i Løverdags findes i Prædicant-Listen anmeldt for Vartou Kirke: "Ingen Aftensang". I denne Anledning maa jeg tjenstligst anmode Deres Høiærværdighed behageligen at ville skaffe mig Oplysning om, efter hvilken Bemyndigelse den anordnede Aftensang denne Søndag er bortfalden." -

I Anledning heraf maa jeg anmode Deres Velærværdighed om at meddele mig den af Herr Biskopppen forlangte Oplysning. -

Khvn. d. 17. April 1844

E. Tryde

Velærværdige

Herr Pa[s]tor Grundtvig

R. a. D.! -

\section{Til E. Tryde}

Deres Høiærværdighed har, under Dag[s] Dato, paa Embeds Vegne, afkrævet mig Oplysning om det, naturligviis nærmest for mig stødende og ærgerlige, "Ingen Aftensang" i Adres-Avisen; men naar denne Sag skulde findes en Undersøgelse værd, maatte den vel begynde paa Adres-Comptoiret, hvis Tankegang ved denne Leilighed jeg ei har kunnet opdage og kan da end mindre give nogen Oplysning om!

ærbødigst

N. F. S. Grundtvig

S.T.

Hr. Stiftsprovst Tryde

R. a. D. og Dbmd

i Kiøbenhavn 


\section{Fra E. Tryde ${ }^{5}$}

Hvor ugjerne jeg end videre fortrædiger Deres Velærværdighed i Anledning af det tidligere berørte Avertissement i Adresseavisen fra afvigte Løverdag, maa jeg dog i Anledning af Deres Yttring i Deres Svarskrivelse, som jeg modtog i Gaar, at Undersøgelsen om hiint Avertissement maatte begynde paa Adresse-Comptoiret, hvis Tankegang ved denne Leilighed De ei havde kunnet opdage og derfor end mindre giver Oplysning om, bemærke, at da Avertissementerne om Prædikanterne indgaae fra Prædikanterne selv og meddeles gjennem Kirkebetjenterne, maa Oplysningen vistnok søges i dette Tilfælde hos Deres Velærværdighed, der da selv maa gaae i Rette med Meddeleren eller Avisens Redacteur. - For at opfylde det mig overdragne Hverv maa jeg derfor tjenstligst anmode Dem om, at meddele mig Deres Erklæring om, at Avertissementet er indrykket uden Deres Vidende ved en eller anden Misforstaaelse fra vedkommende Meddeler eller Redactions Side.

Khv. d. 19. April 1844

E. Tryde

Velærværdige

Herr Pastor Grundtvig R. .a. D.! -

\section{Til E. Tryde ${ }^{6}$}

Deres Høiærværdighed

Svag som jeg er, saa jeg knap kan røre Pennen, er det vist nok haardt to Gange at kaldes til Regnskab for et tosset Avertissement i Adresavisen, hvori jeg har hverken Lodd eller Deel, thi jeg troede dog ved at fralægge mig det at have gjort Alt hvad man kunde ford[r]e.

Er det derimod Afholdelsen af Aftensang i Vartou en Confirmations-Søndag da jeg neppe var istand til at forrette Tjeneste, man vil kræve mig til Regnskab for, da veed dog vist Deres Høiærværdighed, hvad der er hele Byen vitterligt, at i Mands Minde har ingen Præst ved Vartou selv saa omhyggelig besørget Aftensangen, saa en Irettesættelse derfor kunde jeg godt bære naar jeg ikke som nu var saa svag at den mindste Byrde hviler centnertungt paa mig.

Kiøbenhavn 19de April 1844.

ærbødigt

N. F. S. Grundtvig 


\section{Fra P. A. Fenger ${ }^{7}$}

Kjære Hr. Grundtvig!

Slotsbjergbye d. 26de April 1844.

Uagtet jeg seer af Aviserne at De har prædiket, hører jeg at De dog bliver ved at skrante. Det gjør mig ondt. Vorherre holde sin Haand over Dem. Naar Veiret, som vi haabe snart bliver blidt, saa tag en lille Tour paa Landet. Vilde De paa en saadan gjæste mig saa veed De nok hvor glad jeg blev.

Harald Boisen har jo nok fortalt Dem hvad Indtryk Efterretningen om den Vending det havde taget med Psalmesagen ${ }^{8}$, gjorde paa os, at vi syntes vi maatte gjøre en lille Diversion, at jeg skulde forsøge at skrive et Stykke hvortil de andre Conventbrødres Erklæring kunde knytte sig, at jeg gjorde det, men at det ikke vandt Bifald, at derfor en anden Erklæring, som i Conventet blev opsat af [P. C.] Kierkegaard, og der discuteret, blev antaget og underskrevet og indrykket $i$ den Berlingske Tidende, at jeg dog lod mit Besyv trykke i den lille Bog, hvoraf jeg haaber at C. Boisen, efter min udtrykkelige Anmodning, har overleveret Dem et Expl. Den Erklæring som, efter mit Forslag, skulde knyttes til hvad jeg havde skrevet var kortelig denne: at idet Enighed i Hovedsagen med de fremsatte Anskuelser tilkjendegaves yttredes:

1) at et Tillæg til den evangelisk christelige Psalmebog var utilstrækkeligt til at afhjælpe Savnet og at derfor Udarbeidelsen af en Ny anbefaledes

2) at navnlig et Tillæg som det der i Udkast er forelagt Publicum ikke vilde være istand til at tilfredsstille den tilstedeværende Trang

3) at vi anseer det for sandsynligt at, under de nærværende Omstændigheder det Kjøbenhavnske geistlige Convent, bedst vilde være istand til at samle en Psalmebog, der kunde blive tilfredsstillende for de Fleste og at vi derfor paa det indstændigste anbefalede at det maatte blive opsat med at indføre det Tillæg, som udarbeides af den liturgiske Commission til det geistlige Convent havde forelagt Regjeringen og Publicum den Psalmebog, som det nu var i Begreb med at samle.

Men, som sagt, det Forslag vandt ikke Bifald, det var vist ogsaa bedre at det gik som det gik, uagtet jeg ikke nægter at Erklæringen i Berlingeren ikke var efter mit Hoved, og tabte al Saft og Kraft ved den Mishandling den var udsat for under Discussionen i Conventet.

Jeg har skrevet Birchedahl til ...

...faa sin Ret i Psalmebogen. De andre 2 var Clausen og Boisen, og Hensyn er i Valget af os 3 vist taget til, at vi ikke boe længer fra hinanden end at vi ugentlig kunne komme sammen for mundtlig at 
forhandle hvad vi hjemme hver for sig have udarbeidet. Jeg har Iver for Sagen; om med Kundskab er et andet Spørgsmaal.

De 200, De skrev om sidst, haaber jeg skal være hos Dem 1 ste Octbr. ${ }^{10}$ Udfaldet af Ritualsagen i det geistlige Convent den Dag De var borte, morede og glædede os at erfare. Her ere vi alle ved godt Helbred naar undtages lidt Skranterie imellem hos Børnene, og at min Kone ikke er stærk og derfor yderligt maa tage sig i Agt.

Hilsen til Deres Kone og Børn fra Deres taknemlig hengivne $P$. Fenger.

\section{Til Gunni Busck ${ }^{11}$}

\section{Kiære Ven!}

Khvn. 2den Mai 44.

Da Hovedet ei endnu staaer ganske rigtig paa mig, har jeg besluttet, vil Gud, at reise lidt rundt i Sælland med hele Familien, og, skiøndt det, efter Omstændighederne, er lidt nærgaaende, kan jeg jo dog ikke reise Landet om, uden at komme til Stifts-Bjergby. Der tænker jeg da at indtræffe Fredagen før 6te Søndag, fra Slots-Bjergby, hvile paa Sabbaten og Søndagen, og da, om Mandagen med mine Sønner, paa den nemmeste og korteste Maade, Du kan optænke, besøge Odden, for derpaa at vende Næsen hjem til Pindse.

$\mathrm{Nu}$ veed $\mathrm{Du}$ min Agt og vil, det veed jeg, gierne see din Ven. Hils din kiære Kone og beed hende være kiæk!

Din

N. F. S. Grundtvig

Jeg agter at reise imorgen med Damperen til Møen.

\section{Fra Gunni Busck ${ }^{12}$}

"Gud velsigne Dig i din Barndom!["]

Stiftsbjergbye 2den Mai 1844

Det var mit Hjertes Bøn for Dig min kjære Ven! og det er saa endnu og vil med Vor Herres Hjelp blive indtil Enden.

Det hvorfor jeg nu skriver Dig til er - din Altergang, som jo skulde skee engang i denne Maaned. Men nu ligger det mig paa Hjerte at vide, om Du helst ønsker, at jeg skal komme, vil Gud, ind i næste Uge, eller i Ugen efter Christi Himmelfartsdag; thi, ihvorvel jeg, naar det var Dig det Samme, helst bliver til den 19de er forbi, saa er det mig dog i Sandhed det Kjoereste, at gjøre det, som Du ønsker det, da jeg kan begge Dele. 
Altsaa vil Du have mig ind i næste Uge faaer jeg da et Brev paa Søndag den 5te Mai; men faaer jeg ei et Saadant, da bliver jeg, som sagt, endnu et Lidet.

Gud gjorde det saa godt med Charlotte Bøgh; hun fik tvende nysselige Smaapiger, der med hende befinde sig vel.

Gud har ogsaa gjort det godt med Gutfeld ${ }^{13}$; thi Han har taget ham til Sig, lukket Døren til mellem ham og Verden, medens det Onde farer over; men om en "liden Stund" saa bliver Guds Miskundhed ogsaa mod denne troende og kjerlige Sjel aabenbar.

Ja ikke en Eneste Sjel, som er af Sandhed, kan vises bort fra den ligesaa milde som mægtige Faderhaand; men hvad der indtil Enden beviser sit Had mod Sandhed, det viser at det maa skilles fra Sandheden saa der bliver det svælgende Dyb imellem. Dog saalænge vi kunne haabe for nogen Sjel o Gud lad Du os haabe, at den ved din Naade kan blive ædru af Djævelens Snare!

$\mathrm{Nu}$ venligst Hilsen til Dig min kjære Ven og Dine. Gud bevare Eder!

Din Ven

G. Busck

\section{Fra Caroline Amalie ${ }^{14}$}

Hr Pastor Grundvig!

Store Bededag [3/5-1844]

Inden de forlader os maae jeg paa det hjerteligste hilse paa Dem ved disse Linier og ønske Dem Guds Velsignelse til Reisen.

Naar de hjemkommer haaber jeg at hilse paa Dem under de grønne Bøge i Sorgenfri. Lad mig nu see at De kommer lige saa rask og forynget tilbage fra Reisen i Sjælland, som ifior fra den engelske. ${ }^{15}$

Guds Fred!

Caroline Amalie

11. Fra Caroline Amalie til Baronesse Stampe ${ }^{16}$

(Afskrift ved Baron Holger Stampe)

$[18 / 5,1844]$

Kjære Baronesse Stampe!

Jeg er Dem uendelig forbunden for Underretningen om vores kjære Grundvigs Behov af Landluft i Sommer, jeg skal sørge for at han faaer et passende Landsted. Hvor gjerne overlod jeg Dem den Glæde at samle Bidrag, og stak mig selv bag ved Dem, som Æren egentlig tilkommer, thi hos Dem opstod Tanken om Ophold paa Landet; dog 
naar Gaven til et sligt Ophold kommer fra Kongen og mig troer jeg at den mindst saarer hans delicatesse, og at glæde og vederqvæge denne kjære Ven er jo Hovedhensigten. Gud ophold ham endnu længe denne Kjæmpe Aand, denne Prophet der ei gjælder i sit Fædreland fordi han seer en Menneskealder forud ind i Fremtiden. Hans Bortgang ville være mig og den lille Flok der med Hjertet hænger ved ham et uopretteligt Tab!

Hvor er det mig kjært, at jeg ganske deler Deres Begeistring for de udmærkede Aander! - Gud opvække mange saadanne i det ubeskrivelig elskede Danmark!

Min venligste Hilsen til alle Nysøes Beboere, først og fremmest til Dem Selv!

Sorgenfrei, Den 18. Mai 1844 Caroline Amalie

\section{Fra Gunni Busck ${ }^{17}$}

“Æres Den, som Æren hører til."

Stiftsbjergbye 23de Mai 1844

Det var Dig ikke tiltænkt af mig, at Du ved din Ankomst til Kbh. skulde finde skriftligen en broderlig Hilsen og mit Hjertes "Guds Fred $i$ dit Huus!" men kjære Ven! Da nu Vor Herre sendte mig disse indlagte Breve med Posten igaar og jeg skal sende dem bort idag, saa var det saa tomt med en bar Convolut og derfor seer Du ogsaa her Sort paa Hvidt for hvad der er Aand paa mit Hjertes Kjødtavler og hvad jeg haaber evindelig forklaret i vore Hjerter af den hellige Ild, Han er kommen at tænde og har tændt paa Jorderig, saa "det sig bør altid at vi sjunge med Englene: Ære og Priis være Gud i det Høie Halleluja! Paa Jorderig Fred og hos Menneskene Fornøielighed ${ }^{*}$ ) i Gudsbarnets Jesu velsignede Navn!

Mange mange venlige Hilsener fra os til Jer Allesammen og til din Kone særskilt fra mig Ønsket ja Bønnen for hende til Gud, at dette falleds Fader Vor maa vare et evigt Fadervor!

Din Ven

Gunni Busck

*) Jeg er saa fornøiet med min Gud sagde altid gl. Madame Grene ogsaa naar hun leed paa Legemet og den gamle blinde fattige i mange Aar sengeliggende Enke paa Frederiksberg sagde altid med saadanne milde Taarer og en brudt Stemme: Jeg kan ikke Gud fuldtakke! og saa 
sukkede hun i Aanden, som vilde hun op til Ham, at takke fuldt og atter min Ven: "Halleluja!" thi hun er der!

\section{Fra Caroline Amalie ${ }^{18}$}

Hr Pastor Grundvig

[25. maj, 1844]

Hvor det overraskede mig at see Dem i Dyrehaugen i Aftes, og saa vel og munter af Udseende! Gud være lovet!!! Da jeg kom hjem fandt jeg Deres kjære Brev, og blev ret sjæleglad over at erfare af samme og dernæst ved et Brev af Peter Boisen at De selv og Familie samtykke i Kongens og Dronningens Ønske at De tilbringer Sommeren paa Landet i frisk og sund Luft. Nu havde vi rigtignok ønsket Dem baade en videre Udsigt over Sundet og det majestætiske Rygstød af Dyrehaugen, men i en christelig Atmosphære vil de leve i Tuborg, thi lige overfor i Gammel Vartov lever eet af Herrens meest elskede Børn, dette tør jeg dristigen paastaae. Denne meest quindelige Quinde er for Øieblikket hos Moderen i Kiel men snart vender hun tilbage.

Jeg erfarer nok naar De først er flyttet ind paa Tuborg, og da skjænker De mig et kjært Besøg paa Sorgenfrie.

Med sand Hengivenhed 25. Mai

Caroline Amalie

\section{Fra Gunni Busck ${ }^{19}$}

1ste Pintsedags Aften [26. maj] 1844 Ja Du maa da ikke være Stedbarn kjære Ven! da jeg skriver i Øster og Vester om den store Dreng, Gud imorges kl. 7 gav os. Ja Han gjør det vel Altsammen og, naar vi ret har faaet nye Hjerter til at kjende det $\mathrm{i}$ Sandhed, saa skulle vi med Jesu Hjelp sige Ham det deroppe i Guds Børns Forsamling: Ja søde himmelske Fader! Du gjør det vel Altsammen!

At Du ogsaa har havt en velsignet Pindtsefest - derom tvivler jeg ei; thi det vilde Han jo give og hvo kan da hindre det. "Det er ordentlig en saa betryggende Følelse at vide Gr. igjen her i Byen; jeg glæder mig inderlig til imorgen!" skrev Molly Bech igaar herud og Gud har vist ei idag beskjæmmet hendes Haab; men viist det, som Han pleier, at Han gjør langt mere end vi kunne bede Ham om og forstaae! nemlig vel, at vi har bedet Ham om Saameget. - Min kjærlige gamle Moder bereder mig i sit Brev idag paa, at nok ikke jeg, men en Provst fra Fyen faaer Brøndbyvester; hun vil ikke have - skal jeg sige Dig - at det skal 
bedrøve mig. Og som jeg tænker med Kjerlighed paa hende den trofaste kjære Sjæl for hendes Kjerlighed saa føler jeg dybt og inderligt hvor dog Han tænker paa os og har Omsorg for os og bærer og pleier og velsigner os den himmelske Fader, som har tegnet vore Navne i sine Hænder. Hans Villie og ene Hans Villie den give Vor Herre Jesus os at elske og lyde og følge, som Han i sit Kjøds Dage elskede og lød og fulgte den!

Vær nu hilset og hils dine Kjære og Gud velsigne os og bevare os; thi baade kan Han det og Han vil det - Hans Navn være lovet!

Din Ven

Gunni Busck

\section{Til Ferdinand Fenger ${ }^{20}$}

Khvn 28de Mai 1844.

Kiære Ven!

Tak for Deres kiærlige Modtagelse og venlige Besøg, og Tak for Tonerne, De har været med at kalde frem til Vuggevisen, som Smaapigerne igaar sang for mig, uden at jeg savnede Andet end "MadikeTunge" der i Engle-Mund passer bedst til os daarlige Efterlignere af Ham, der sagde "jeg er en Orm og ikke en Mand," og er desuden en gammel Medicin for min gamle Adam. Hils nu Kora ${ }^{21}$ mange Gange med Tak for hendes gamle Godhed for mig og min Sang, og spørg, om hun ikke kunde falde paa en smuk Melodi til Pindse-Sangen

Talsmand, som paa Jorderige

Med et Suk kan Alt udsige,

ikke fordi jeg foretrækker den umaadelig, men fordi jeg seer, at Hjorth og Flere giør det og finder, den kan ogsaa være god, naar den faaer Gænger.

Vuggevisen har ellers faaet et Indskud som 2det Vers:

2

Med Fingrene sande

Slaae Kors for din Pande!

Med Gudsbarnets Røst

Slaae Kors for dit Bryst!

Saa kan ingen Djævel dig giæste;

Saa skal om din Daab,

Med Saligheds Haab,

Sig Mindet i Barmen rodfæste.

Hos mig slutter den ogsaa først saaledes:

5

Da alle de Kiøbte, 
I Jesu Navn Døbte,

Som Striden har stridt,

Som Døden har lidt,

Gik ind til den evige Hvile,

Istemme saa lydt

Halleluja nyt,

At Englene tie og smile.

6

Sov sødt, Barnlille!

Lig rolig og stille

Og nyn paa det Navn,

Med Fylden i Favn,

Al Jorden til Salighed givet!

Nyn: Jesus er min,

Saa faur og saa fiin,

Min Jesus er Lyset og Livet!

Min Kone løb fra mig i Roskilde, og vi Andre, Drengene og jeg, kom ikke længer end til Frederiksborg, hvor Nattergalen sang saa deilig, at jeg fandt, Sommeren, som jeg reiste efter, var nu fuldelig naaet og gav indtil videre Helsingør en god Dag.

Vi overraskede altsaa min Kone Torsdag Eftermiddag, men hun overraskede os igien med det Budskab, at, efter Dronningens Villie og med Kongens Vidende skulde vi ligge paa Landet i Sommer! Lille Tuborg er nu valgt til Residens, og det morer mig blandt Andet at "Gammel Vartou" ligger lige over for. Hils Rikke, at jeg kommer igien, og naar De seer Venner som Deres Broder, Ingemann, og Kierkegaard, da hils ogsaa dem paa det Kiærligste fra Deres N. F. S. Grundtvig.

$$
\text { 16. Til Gunni Busck }{ }^{22}
$$

Kiære Ven!

Khvn. 5te Juni 1844.

Paa Østerbro kom der to Fugle flyvende ud af Nattegale Reden og sang om Brøndby-Vester, saa det maa jo være vist, og skiøndt jeg kun beærer Hovedstaden med et kort Besøg, maa jeg dog tage mig Stunder til at ønske Dig Guds Naade og Velsignelse ovenikiøbet, saa Du kan blive rig!

Naar nu Dronningens Fødselsdag kommer, da siger vi: det er afgjort for længe siden, men Gud velsigne Hendes Majestæt!

Hils kiærligst Alle omkring Dig fra os og ei mindst fra

Din

N. F. S. Grundtvig 


\section{Fra Gunni Busck ${ }^{23}$}

Stiftsbjergbye 6te Junii 1844 Ja kjære Ven! kommer jeg nu til Brøndbyvester, som jeg efter al Rimelighed gjør, saa kommer jeg der jo, som jeg skrev til Dig i Vinter "kaldet af Guds Naade ved Ordet, som udgaaer af Kongens Mund, der haver Alt at raade"; idetmindste veed jeg ikke andet med mig selv end at jeg har bedet og beder og vil med Jesu Hjelp altid bede: "Skee Guds Villie!" Saa velsigne Gud ogsaa af sin Naade vor Omgang at vi maae være det for hinanden, hvoraf vi kunne have stor og blivende Glæde, naar vi med Jesu Hjelp ere i Ordets egentligste og deiligste Forstand: "Ovenpaa!"

Hils hjerteligst Dine og vær saaledes hilset fra mig og Mine!

Din

Gunni Busck

\section{Fra Gunni Busck ${ }^{24}$}

Stiftsbjergbye 1st Juli 1844 Inderlig Tak kjære Ven! fordi dit Hjerte tænkte paa mig og undte mig Fornøielsen af Festen paa Skamlingbanke ${ }^{25}$; men Du kan ikke vente at see mig i Callundborg, da jeg ei tør begive mig paa de vaade Veie; derfor kan jo Vor Herre, som har saa mange Veie i sin Haand, godt føre mig ad en anden Vei, naar Han engang vil, til "Skamlingbanken".

Lev nu vel og, naar vi nu sees, kunne og maae vi tale om vor lille Søns Daab, at han snart kan modtage, eller vi paa hans Vegne, den Trofastes Løvte om den evige Velsignelse!

Med hjertelig Hilsen og Bøn til Gud om det evige Fadervor mellem de aldrende Ægtefolk!

Din Ven

G. Busck

Forkortelser

$B G$ II: Georg Christensen og Stener Grundtvig (udg.) (1926), Breve fra og til N. F. S. Grundtvig, bind 2, København.

Fasc. $=$ Fascikel, dvs. håndskriftskapsel i N. F. S. Grundtvigs arkiv på

Det Kongelige Bibliotek.

NBD (Nyere Brevsamling, dansk), Det Kongelige Bibliotek.

NKS = Ny Kongelig Samling, Det Kongelige Bibliotek. 


\section{Litteraturliste}

Bech, Henr. (udg.) (1878), Gunni Busck, et Levnedsløb $i$ en Proestegaard, 2. udg., København.

Christensen, Georg og Stener Grundtvig (udg.) (1926), Breve fra og til N. F. S. Grundtvig, bind 2, København.

Ertner, Jørgen (1997), "Et ord af Guds Søn”, Grundtvig-Studier 1997, bind 48, København, 185-211.

Rosendahl, H. (1944), "Et Aar af Grundtvigs Liv 1844" i Højskolebladet, København, $306 \mathrm{ff}$.

Rørdam, H. F. (udg.) (1891), Peter Rørdam. Blade af hans Levnedsbog og Brevvexling fra 1806-1844, 1. del, København.

Thodberg, Chr. (2005), "Grundtvigs krise i foråret 1844. Forholdet mellem prædiken og salme med henblik på 'Sov sødt, Barnlille'” i Grundtvig-Studier 2005, København, s. 38 ff.

\section{Noter}

1 Brevet er udateret, men efter indholdet at dømme sandsynligvis fra dagene lige inden påske 1844 .

I manuskriptet, fasc. 450, er skrevet til med fremmed hånd i øverste højre hjørne: "1844”. En anden hånd har tilføjet: "Nej 1843, da Kongens Besøg fandt Sted 4/5-43, hvis han ej var der oftere!"

Kongens besøg på Dronningens skole i 1844 kan være det besøg, Peter Rørdam foreslår $\mathrm{i}$ brev til Dronningen før påske, refereret $\mathrm{i}$ brev til Grundtvig 5. april 1844. (Rørdam 1891, 307).

2 Fasc. 460. Den 30. marts 1844 er lørdagen før Palmesøndag, hvor Thorvaldsen begraves, og Grundtvig er syg.

3 Fasc. 408.

4 Fasc. 408. Brevene 4 og 6 til E. Tryde findes trykt i $B G$ II, 391, men bringes her for sammenhængens skyld.

Fasc. 408.

Fasc. 408.

7 Fasc. 462. De anførte dele af brev fra P. A. Fenger til Grundtvig er udeladt i de trykte breve BG II, 391 f., og skal indsættes, hvor den trykte udgave har 4 tankestreger.

Jf. $B G$ II, 390.

Se herfra videre brev nr. 489 i $B G$ II, $391 \mathrm{f}$.

10 Jf. $B G$ II, 390.

11 Fasc. 460.

12 NKS 2710, 2 O.

13 Provst Gutfeld, svigerfader til Gunni Busck fra første ægteskab med Andrea Gutfeld. 
14 Fasc. 450.

15 Jf. $B G$ II, 375.

16 Fasc. 450. Brevene 11 og 13 er delvist gengivet i Rosendal 1944, 306 ff.

17 Fasc. 460.

18 Fasc. 450.

19 Fasc. 460.

20 NBD 2. rk.

21 Cora Nyegaard.

22 Fasc. 460.

23 Fasc. 460.

24 Fasc. 460.

25 Jr. BG II, 401. 